\title{
How We Managed Primary Immunodeficiency Disorders in Pakistan - A Case Based Study
}

\author{
Asifa Noor ${ }^{1, *}$, Mehjabeen Imam², Tasneem Farzana ${ }^{3,4}$, Saqib Ansari1 ${ }^{1,3}$, Uzma Zaidi³,4, Saima Munzir ${ }^{3,5}$ \\ and Tahir Sultan Shamsi ${ }^{3,4}$
}

${ }^{1}$ Department of Pediatric Hematology, National Institute of Blood Disease \& Bone Marrow Transplantation, Karachi, Pakistan.

${ }^{2}$ Department of Transplant Immunology, National Institute of Blood Disease \& Bone Marrow Transplantation, Karachi, Pakistan.

${ }^{3}$ Department of Clinical Hematology, National Institute of Blood Disease \& Bone Marrow Transplantation, Karachi, Pakistan.

${ }^{4}$ Department of Bone Marrow Transplantation, National Institute of Blood Disease \& Bone Marrow Transplantation, Karachi, Pakistan.

${ }^{5}$ Department of Clinical Genetics \& Genomics, National Institute of Blood Disease \& Bone Marrow Transplantation, Karachi, Pakistan.

Introduction: This article emphasizes on the importance of time frame for diagnosis and management of immunodeficiency syndromes and also highlights the diagnostic dilemma that most often such cases are misdiagnosed or undiagnosed which contributes to significant morbidity and mortality.

Case Presentation: This article with the help of five exemplary cases illustrates the different types of primary immunodeficiencies including severe combined immunodeficiency (SCID), and their varied clinical presentations and management and also describes the difficulty in reaching final diagnosis and a brief review of literature on primary immunodeficiency and its therapeutic approach.

Management and Outcome: All the patients described in this case based study underwent Hematopoietic stem cell transplant; the definitive therapeutic approach for all kinds of immunodeficiency syndromes. Four out of five patients were successfully treated, unfortunately one could not survive.

Discussion: The purpose of this article is to raise public health awareness regarding prevalence of primary immunodeficiency disorders and their possible cure via hematopoietic stem cell transplant, if diagnosed and managed promptly.

Keywords: Primary immunodeficiency disorder, Severe combined immunodeficiency, Hematopoietic stem cell transplantation, Graft versus host disease, Myeloablative conditioning therapy, Hypogammaglobinemia.

\section{INTRODUCTION}

Primary Immunodeficiency Disorders (PIDs) are a diverse group of more than 250 inherited disorders of immune system that are characterized by altered inflammatory response and immune dysregulation, leading to development of recurrent infections and malignant transformation [1].

All forms of PIDs are rare and worldwide incidence of PIDs is variable ranging from around 1 in 10,000 to 3 in 100,000 live births except IgA deficiency which is comparatively common and incidence is 1 in 600 live births [2, 3]. PID registries are established in several countries to determine the incidence and prevalence of the disease [4-6]. In Pakistan, no such registry has been established so far and no studies have been done regarding the incidence and prevalence of PIDs. Autosomal disorders are more prevalent in countries with high consanguinity [7]. In under developed countries with higher

*Address correspondence to this author at the Department of Pediatric

Hematology, National Institute of Blood Disease \& Bone Marrow

Transplantation, Karachi, Pakistan. E-mail: drasifanoor@gmail.com rate of consanguineous marriages, these disorders remain under diagnosed and infants die early due to life-threatening infections. The International Union of Immunological Societies (IUIS) Expert Committee on Primary Immunodeficiency reclassified PIDs in 2015. Major categories were broadly included in different groups as given in the Table $\mathbf{1}$ [8].

The most common clinical manifestation of immunodeficiency is recurrent infections. In resource constraint regions, the presence of confounding factors like unhygienic living conditions may be attributable to development of recurrent GI infections, TB and other communicable infections, which may lead to diagnostic ambiguity. Recurrent infections involving lungs, meninges, blood stream, skin, gut and liver from infancy onwards should alarm the treating paediatrician about the possibility of a PID. In the absence of efficient immune system, causative organisms do not easily respond to anti-microbial agents.

www.njhsciences.com 
Recurrent episodes of serious and life-threatening infections like pneumonia, meningitis, septicaemia, chronic skin infections, diarrhoea, and hepatitis result in death within first

Table 1. Classification of Primary Immunodeficiency Disorders [8].

\begin{tabular}{|l|l|}
\hline No. & \multicolumn{1}{|c|}{ Category of Disorders } \\
\hline 1. & $\begin{array}{l}\text { Immunodeficiency affecting cellular and humeral } \\
\text { immunity (SCID). }\end{array}$ \\
\hline 2. & $\begin{array}{l}\text { Combined immunodeficiency with or without } \\
\text { syndromic features. }\end{array}$ \\
\hline 3. & Predominantly antibody deficiencies. \\
\hline 4. & Diseases of immune dysregulation. \\
\hline 5. & $\begin{array}{l}\text { Congenital defects of phagocyte number, function, } \\
\text { or both. }\end{array}$ \\
\hline 6. & Defects in Intrinsic and Innate Immunity. \\
\hline 7. & Auto-inflammatory disorders. \\
\hline 8. & Complement deficiencies. \\
\hline
\end{tabular}

Recurrent bacterial infections are more commonly seen in B cell malfunction, phagocytic cell defects and complement deficiency while opportunistic viral and fungal infections are more common in $\mathrm{T}$ cell defects. Beside these features, there are certain other clinical manifestations like age of presentation, non-infectious complications, failure to thrive and family history also provide clue to the diagnosis and underlying immune defect [10]. Earlier age of presentation year of life. PID should be suspected in presence of features highlighted in Table 2 [9].

Table 2. When to Suspect Primary Immunodeficiency Disorders [9].

\begin{tabular}{|l|l|}
\hline No. & \multicolumn{1}{|c|}{ Conditions Requiring PIDs Screening } \\
\hline 1. & $\begin{array}{l}\text { Recurrent infections, e.g., more than } 4 \text { new ear } \\
\text { infections or } 2 \text { sever pneumonia or } 3 \text { serious sinus } \\
\text { infections per year. }\end{array}$ \\
\hline 2. & Severe and life threatening infections. \\
\hline 3. & Complicated and on multiple sites. \\
\hline 4. & Unusual site and organism. \\
\hline 5. & Deep skin or organ abscess. \\
\hline 6. & Prolong IV antibiotics use with little effect. \\
\hline 7. & Persistent oral thrush or skin infection. \\
\hline 8. & Family history of PIDs. \\
\hline 9. & Blood counts are persistently low or high. \\
\hline
\end{tabular}

indicates severe immune deficiency like $\mathrm{T}$ cell defect with or without B cell defect however, common variable immune deficiency (CVID), which is a less severe form of PID, in which patients may present in teenage or adult life. The important and distinct clinical features of different types of PIDs and their screening and diagnostic tests are given in Table 3 [10].

Table 3. Categorization of PIDs according to Site Involved with Possible Screening Tests.

\begin{tabular}{|l|l|l|}
\hline Site of Infection & Possible PIDs & Screening/ Diagnostic Tests \\
\hline $\begin{array}{l}\text { Upper } \\
\text { respiratory tract }\end{array}$ & $\begin{array}{l}\text { Antibody or } \\
\text { complement deficiency }\end{array}$ & $\begin{array}{l}\text { Serum immunoglobulin level, Antibody titer to } \\
\text { protein and polysaccharide vaccines, } \\
\text { isohaemagglutinin, Lymphocyte analysis by flow } \\
\text { cytometry to enumerate B cells, blood complement } \\
\text { assay }\end{array}$ \\
\hline $\begin{array}{l}\text { Lower } \\
\text { respiratory tract }\end{array}$ & $\begin{array}{l}\text { Antibody or complement } \\
\text { deficiency, T cell deficiency, } \\
\text { phagocytic cell defect }\end{array}$ & $\begin{array}{l}\text { Serum immunoglobulin level, Antibody titer to } \\
\text { protein and polysaccharide vaccines, } \\
\text { isohaemagglutinin, WBC count with neutrophil and } \\
\text { lymphocyte count, respiratory burst assay, } \\
\text { Lymphocyte subset analysis by flow cytometry to } \\
\text { enumerate T and B cells, blood complement assay }\end{array}$ \\
\hline $\begin{array}{l}\text { Skin, internal organs } \\
\text { Blood or Central nervous } \\
\text { system including meninges }\end{array}$ & Antibody or complement deficiency & $\begin{array}{l}\text { Respiratory burst assay, CD11, CD18 assay, NBT } \\
\text { isohaemagglutinin, Lymphocyte analysis by flow } \\
\text { cytometry to enumerate B cells, blood complement } \\
\text { assay }\end{array}$ \\
\hline
\end{tabular}


Majority of the patients with primary immunodeficiency are undiagnosed, under-diagnosed, or misdiagnosed. To overcome this diagnostic dilemma, the Jeffrey Medell Foundation has implemented a Physician Education and Public Awareness Campaign (PEPAC). The purpose of this campaign is to identify the global incidence of primary immunodeficiency, risk stratification, ethnic \& geographical distribution of the disease burden and most importantly to create better management options for such patients [11].
The Objective of this paper is to create awareness regarding this rare disease entity, so that prompt diagnostics and management may reduce the morbidity and mortality pertinent to this disorder. These disorders are characterized by defects in both arms of adaptive immune system. The global prevalence of SCID is around $6.7 \%$ of all primary immunodeficiency disorders [5]. Different types of SCIDs and their genotypes are discussed in Table 4 [12].

Table 4. Different types of SCID and their Genetics.

\begin{tabular}{|c|c|c|c|c|}
\hline SCID Type & $\begin{array}{c}\text { Mode of } \\
\text { Inheritance }\end{array}$ & Genetics & Incidence & Diagnostic Work Up \\
\hline T -ve B -ve NK+ SCID & & & $50 \%$ & \\
\hline Omenn syndrome & $\begin{array}{l}\text { Autosomal } \\
\text { recessive }\end{array}$ & $\begin{array}{l}\text { Mutations in RAG1 and RAG } 2 \\
\text { genes }\end{array}$ & $4-20 \%$ & $\begin{array}{l}\mathrm{T} \text { and } \mathrm{B} \text { cell count with } \\
\text { flowcytometry }\end{array}$ \\
\hline Reticular dysgenesis & $\begin{array}{l}\text { Autosomal } \\
\text { recessive }\end{array}$ & $\begin{array}{l}\text { Mutation in Adenylate kinase } 2 \\
\text { gene }\end{array}$ & $1-2 \%$ & $\begin{array}{l}\mathrm{T} \text { cell proliferative response } \\
\text { to mitogen }\end{array}$ \\
\hline \multicolumn{5}{|l|}{ T-ve B-ve NK -ve SCID } \\
\hline $\begin{array}{l}\text { Adenosine deaminase } \\
\text { deficiency }\end{array}$ & $\begin{array}{l}\text { Autosomal } \\
\text { recessive }\end{array}$ & $\begin{array}{l}\text { Missense mutation in ADA gene, } \\
\text { A329V is common among all } \\
\text { mutations }\end{array}$ & $10-20 \%$ & $\begin{array}{l}\text { RBC assay for Adenosine } \\
\text { deaminase }\end{array}$ \\
\hline T-ve, B+ve NK+ve SCID & & & $50 \%$ & $\mathrm{D}$ \\
\hline X linked SCIDs & $\begin{array}{l}\text { X linked } \\
\text { disorder }\end{array}$ & $\begin{array}{l}\text { IL2 receptor Gamma chain } \\
\text { mutation }\end{array}$ & $50-60 \%$ & \multirow{2}{*}{$\begin{array}{l}\mathrm{T} \text { and } \mathrm{B} \text { cell enumeration } \\
\text { by using flowcytometry } \\
\text { Genetic testing }\end{array}$} \\
\hline Jake 3 deficiency & $\begin{array}{l}\text { Autosomal } \\
\text { recessive }\end{array}$ & Mutation in Jak 3 tyrosine kinase & & \\
\hline Other SCIDs & & Transporter protein 2 (TAP2) & $30-40 \%$ & \\
\hline MHC class 1 deficiency & $\begin{array}{l}\text { Autosomal } \\
\text { recessive }\end{array}$ & mutation & Rare & $\begin{array}{l}\text { HLA DR on T and B cells } \\
\text { for MHC class II }\end{array}$ \\
\hline MHC class 2 deficiency & $\begin{array}{l}\text { Autosomal } \\
\text { recessive }\end{array}$ & $\begin{array}{l}\text { Mutation in transcriptional } \\
\text { activators of MHC class II genes }\end{array}$ & Rare & Genetic testing \\
\hline
\end{tabular}

\section{CASE-PRESENTATION}

\section{Case \# 01: T-B-NK-}

One-month-old female child presented to NIBD in 2011 with a history of one sibling's death at the age of 6 months due to SCID. Her diagnostic work up was performed for SCID on second day of life. Her immunoglobulin levels were; IgM $0.20 \mathrm{~g} / \mathrm{dl}(0.08-0.4), \operatorname{IgA} 0.12$ (0.02-0.15), IgG 3.0 (3.9-13). ALC $0.8 \times 10^{9} / \mathrm{L}$; Lymphocyte subset analysis revealed these findings: $\mathrm{CD} 3+\mathrm{CELLS}$ 0.0, CD3+ CD4+ cells 0.0, $\mathrm{CD} 3+\mathrm{CD} 8$ cells $0.0 \%, \mathrm{CD}+190.45 \times 10^{9} / \mathrm{L}$ and $\mathrm{CD} 16+\mathrm{CD} 56$ cells $0.26 \times 10^{9} / \mathrm{L}$.

On the basis of above lab tests, she was diagnosed as having SCID, with a phenotype T-B-NK- (ADA-deficiency). She was found to be full HLA match with her elder sibling. HSCT was performed using bone marrow as a source of stem cells without any conditioning regimen. She didn't receive any GVHD prophylaxis [13].

She had an uneventful recovery with lymphocyte engraftment on day +40 . She remained well all along with full immune reconstitution and maintained full donor chimerism. This case highlights the importance of following a timely diagnostic algorithm as depicted in Fig. (1) and implementation of adequate management options, i.e., early transplant, leading to favorable outcome.

\section{CASE \# 02: (T-B-NK-)}

A 4 months old female child (product of consanguinity), presented with complaints of abscess formation at BCG injection site, which was given at birth as part of regular 


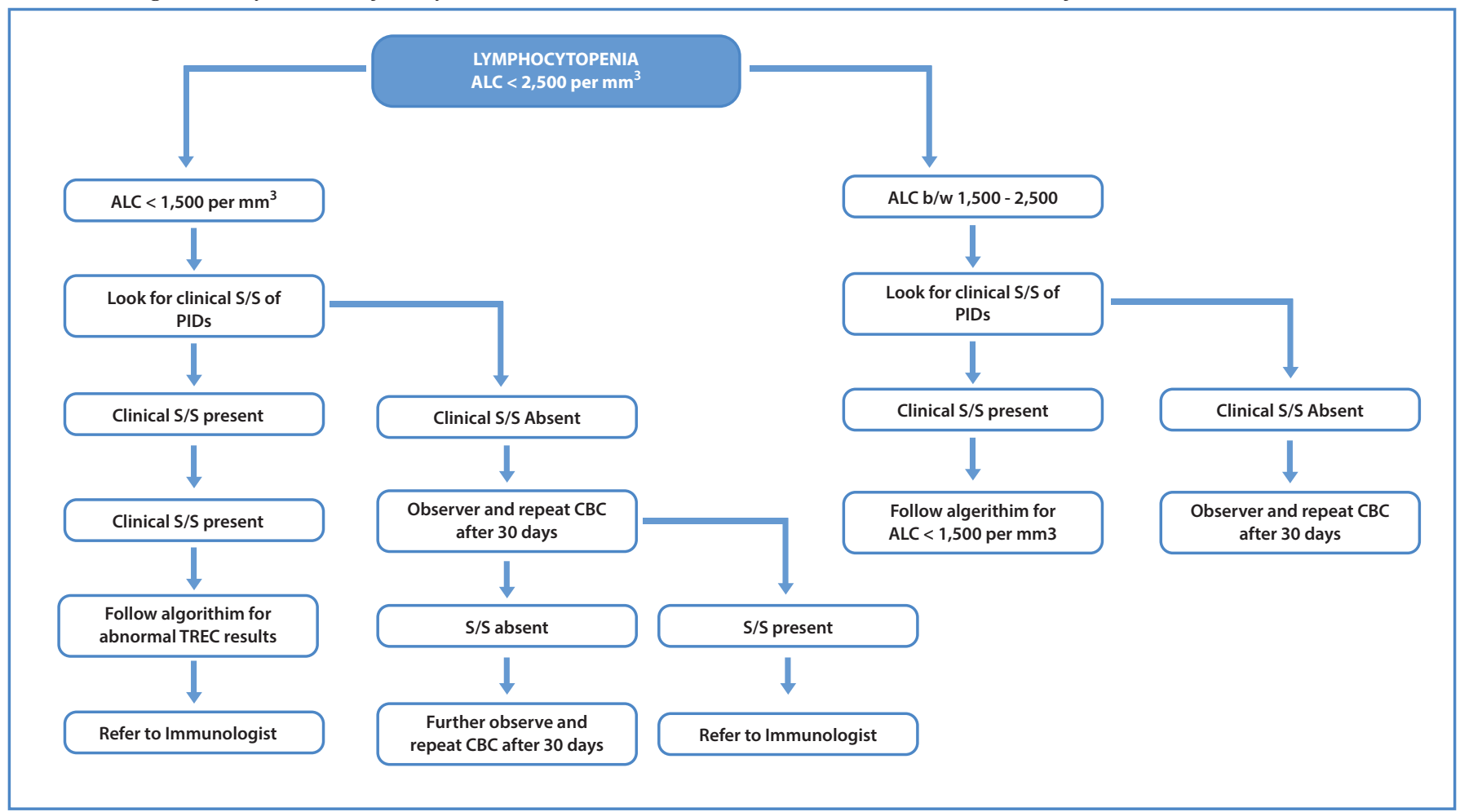

Fig. (1). Diagnosis of SCID.

vaccination given to neonates in Pakistan. She had failure to thrive, and fever on \& off. She had been to various pediatricians and finally was referred to NIBD in 2015 for work up and treatment. Her SCID workup showed completely absent T, B, and NK-cells while immunoglobulin levels were also extremely low. Phenotypically she was T-B-NK- SCID (ADA deficiency). Her parents were counseled regarding nature of the disease and its definitive treatment option i.e., HSCT. Her mother was selected a haploidentical donor for him. She was immediately hospitalized \& after optimization, she was proceeded for HSCT. No conditioning therapy was given to her, neither any GvHD prophylaxis. She had an uneventful course during hospitalization for HSCT and was discharged on day +30 when her absolute lymphocyte count (ALC) started to rise. During regular BMT-OPD follow-up, it was noted that her ALC showing a declining trend. At six month post-transplant, ALC were alarmingly low although she remained clinically well. Parents were counseled for the loss of her marrow graft; Stem cells reinfusion was carried out with mother being the donor without any conditioning regimen. GVHD prophylaxis with cyclosporine was instituted.

She engrafted again at day +34 and his ALC continued to rise. At 6 months post second stem cell infusion, ALC count showed completely normal T-cells and NK-cells while B-cells remained sub-normal [14]. She started to produce all immunoglobulin, although the levels were marginally below normal. She has been doing well since last 24 months.
Genetic counseling of this couple was done highlighting the pattern of disease inheritance and importance and availability of prenatal diagnostic facility at our institute. No genetic mutation attributable to SCID was identified in Chorionic villus sampling performed on subsequent pregnancy and the family was blessed with a healthy female child.

This highlights the importance of genetic counseling while dealing with autosomal recessive disorders. Prevention of life-threatening inherited diseases is of utmost importance and is the responsibility of healthcare professionals looking after children with such disorders.

\section{Case \# 3: T-B-NK+ (Omenn Syndrome)}

An 18 days old male presented to NIBD in 2018. He was a product of consanguinity; he came with complaint of rash over face, neck and upper chest;initially the rash was pustular with erythematous base, non-tender, non-desquamating, non-pruritic and without signs of overlying inflammation. The parents were concerned as their elder boy expired last year when he was two and a half months old with similar rash, fever and diarrhea. He was admitted in a Paediatric ICU, where despite of symptomatic treatment, did not survived. This newborn, keeping in view of his sibling's history, had a SCID workup on the day of presentation, which confirmed that he is suffering from primary immune deficiency, with a phenotype of T-B-NK+ Variety. Molecular genetic studies on Next Generation Sequencing (NGS) revealed homozygous RAG-2 mutation. On the basis of these findings, history and clinical presentation, a diagnosis of Omenn syndrome was made [15]. 
Patient was admitted the very same day and a plan for an urgent allogeneic haematopoietic stem cell transplantation (HSCT) was made. His HLA typing did not fully matched with elder sister and both parents. Parents were counseled for haploidentical transplant from elder sister as donor. Appropriate conditioning therapy including antithymocyte globulin (ATG), Fludarabine, pre \& post-transplant cyclophosphamide was given as GvHD prophylaxis. Bone marrow transplant was performed when he was 22 days old. Full supportive care was given during his stay, graft versus disease (GvHD) prophylaxis, (cyclosporine and mycophenolate mofetil) were given during admission. His lymphocyte count started to rise on day +30 and he was discharged from the hospital.

This case enlightens the importance of family history and implies the need of prompt diagnostic workup for immunodeficiency disorders. Early diagnosis and timely management with HSCT has a very high cure rate of up to $90 \%$. Genetic counseling for inheritance of Omenn syndrome, availability of prenatal diagnosis during first trimester of pregnancy should be offered with each pregnancy. Different immunophenotypes of SCID are shown in Fig. (2).

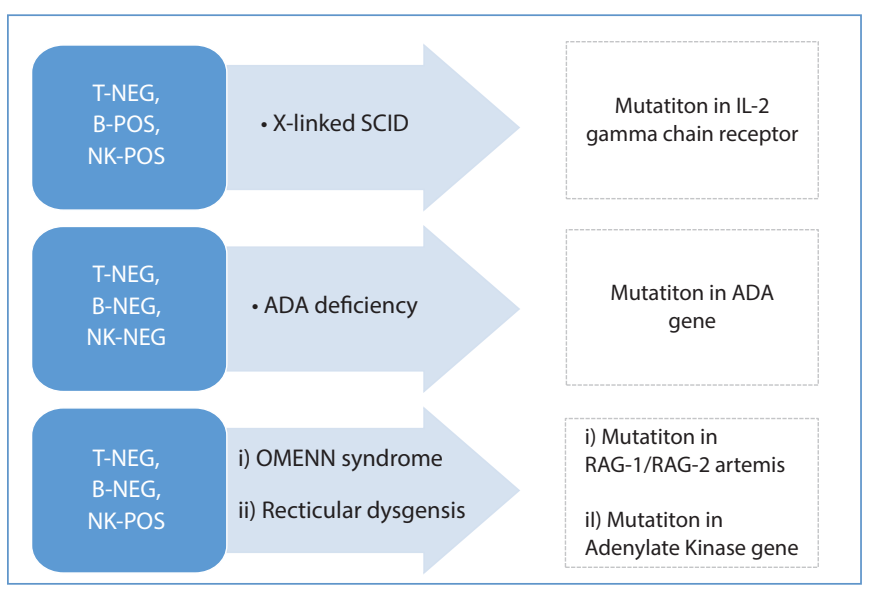

Fig. (2). SCID Immunophenotypes.

\section{Case 04: (CVID)}

A 16-years old boy, resident of Quetta and product of consanguineous - marriage presented with a history of repeated chest infections and unremitting fever. According to the patient he was in usual state of health, till age of four years, after which he developed recurrent chest infections along with fever. He received multiple antibiotics in different healthcare facilities in the country, which provided temporary relief. Because of repeated infections, his general health was poor and his weight was 28 kilogram, below the 50th centile for his age. He had multiple tests done during previous hospitalization, but the diagnosis remained inconclusive.

He came to NIBD in 2014, with a history of multiple hospital admissions due to recurrent chest infections, PID screening was sent at NIBD. Lymphocyte subset analysis showed a low B-cell count while CD4+ T-lymphocytes were also borderline low. Immunoglobulin levels revealed a very low IgG, low IgM and IgA levels. A diagnosis of Combined Variable Immunodeficiency Syndrome (CIVD) was made.

Counseling regarding Bone Marrow Transplant was done and offered allogeneic haematopoietic stem cell transplant from his brother who was HLA identical with patient. For eligibility check, pre-HSCT work up of patient and his donor was done, which turned out to be appropriate. HSCT was performed via peripheral blood. Conditioning regimen including ATG/Fludarabine along with GVHD prophylaxis with cyclosporine was instituted.

His post HSCT follow up remained uneventful. No further episode of infection, or hospitalization occured. He continued to catch up with normalization of his weight and height in subsequent years.

The Key-Message in this case is, the diagnostic-dilemma that this patient faced \& remained undiagnosed till the age of sixteen years. B-cell SCID disorders tends to have late presentation with frequent bacterial infections with or without $\mathrm{T}$ cell dysfunction. There may or may not be T-cell dysfunction. CVID is primary immunodeficiency disorder characterized by significantly low level of immunoglobulin $\mathrm{G}$, immunoglobulin $\mathrm{A}$ and immunoglobulin $\mathrm{M}$ and poor antibody response to vaccines, excluding other primary and secondary causes of hypogammaglobinemia, rendering it to be a diagnosis of exclusion [16]. It is commonest among all clinically significant PIDs and the prevalence is 1 in 25000 50000 of general population. Age of presentation is variable ranging from early onset disorder in more severe forms to later in 2nd or 3rd decade of life. Genetic basis is difficult to determine in most of the patients as in majority of cases, it has got polygenic and complex genetics. The clinical course of disorder is complicated by recurrent bacterial infections involving respiratory tract and gastrointestinal tract resulting in pneumonia, chronic diarrhea and malabsorption. These patients are prone to develop chronic lung disease, autoimmune disorders and malignancies. These patients require lifelong IV immunoglobulin therapy or allogeneic haematopoietic stem cell transplant [16, 17].

Bottom-line is whenever there is a history of recurrent infections in any patients during first few months to few years of life, a differential diagnosis of primary immune deficiency disorders should always be considered and a full battery of screening tests (immunoglobulin levels, lymphocyte subset analysis) should be sent. Subsequent diagnostic tests and management should be done in higher centers where a clinical immunologist and HSCT facilities are available. 


\section{Case 05: (Hyper-IgM Syndrome)}

An 11 year old male child, presented to us in 2005 with complaint of repeated chest infections, on further inquiry it was found that he also had history of multiple hospital admissions with pneumonia and no further work-up was done, except sweat chloride test which was negative. The child was admitted and his diagnostic work up for PID was sent at NIBD. Immunoglobulin levels showed a sub-normal IgG, IgA and $\operatorname{IgE}$ while he had markedly elevated IgM levels. Lymphocyte subset analysis was normal. Patient was diagnosed as a case of Hyper-IgM syndrome. He was started on prophylactic antibiotic therapy and preparation for HSCT started. His brother's HLA typing was full matched with him. He received myeloablative conditioning for allogeneic HSCT [18]. He had an uneventful recovery and discharged home on GvHD prophylaxis and other supportive care drugs. During first 100 days, he was readmitted with acute GvHD involving his gut. He did not respond to first and second line acute GvHD treatment and died because of this complication.

This case again emphasizes the importance of high index of suspicion and low threshold for diagnostic workup of immune deficiency disorders. In SCID patients, history of each episode of infection requiring hospitalization adversely affects the transplant outcome. HSCT done in first three months of life with no or a single episode of infection has an outcome of $>90 \%$. Early diagnosis is possible when there is a positive family history of SCID or recurrent infections.

\section{DISCUSSION}

Management of SCID requires involvement of specialist centre capable of providing comprehensive care to affected children including bone marrow transplantation [19]. Initially, good supportive care to counter infections should be provided and a search for HLA matched donor for bone marrow transplant should be started simultaneously. This requires HLA typing of affected child and siblings and / or parents. A full HLA match donor is preferable but a haplo-identical parental donor or a sibling is a reasonable alternative. Bone marrow transplantation is the only curative treatment for most types.

When a full HLA matched family donor is identified, bone marrow transplant can be performed without any prior conditioning chemotherapy to the affected kid. But this is hardly the case in many patients. Usually a haplo-identical donor is available requiring some immunotherapy and / or myeloablative conditioning therapy. Graft versus host disease (GvHD) prophylaxis may not be given in case of a full match transplant but in other settings $[19,20]$, this prophylaxis is given to prevent GvHD and graft loss. Gene therapy also offers a cure in ADA deficiency and Chediak-Higashi syndrome. But gene therapy is available in only few centres across the globe $[20,21]$.
Bone Marrow Transplant involves harvesting of haematopoietic stem cells from the bone marrow of the donor. In some situations, these cells can be mobilised by using granulocyte-colony stimulating factor (G-CSF) and stem cells are collected from the peripheral blood of the donor. Once harvested, these cells are infused directly to the patient like a blood transfusion. The adequacy of the dose of stem cells is found by counting the number of cells in the harvested product using a flow cytometer. A total dose of more than 4 million cells (expressing CD-34 antigens on their surface) per kilogram body weight of the recipient (patient) is considered adequate [22]. The neutrophils and platelet engraftment of donor origin occurs within first 14-21 days of transplant. While the missing lymphocytes starts to appear in the patient's blood stream after day 28-42 of transplant. During this period, the child is kept in BMT unit in protective isolation and given all the prophylactic measures to prevent any infection. Breast-feeding is recommended during this period as it is a good source of maternal antibodies. Other therapeutic options like ADA enzyme therapy in ADA deficient kids and intravenous immunoglobulin in those kids with absent B-cells are adjunct approaches till a definitive treatment is given [23].

An important consideration is to counsel the couple about the availability of prenatal diagnosis in future pregnancies [24]. This is available in many countries including Pakistan. In affected families, carrier detection is very important along with genetic counselling regarding mode of inheritance of this disease and chances of transmission to the offsprings. In our country, $60-70 \%$ marriages take place within the extended family, bradri or tribe. This makes it very important to provide such counselling to the family members so that the birth of affected children can be prevented. Actual incidence of SCID in Pakistan, like other developing countries, is not known [25]. In USA, the reported incidence is 1 in 1200 [26, 27].

Majority of these patients remain undiagnosed. Only a handful cases are identified each year. By the time the diagnosis is made, they are already in a moribund state. Only a few patients reach to a treatment centre that either already have a history of an affected sibling or parents bring the neonate to a paediatrician/neonatologist for diagnostic workup. An early and timely referral to a transplant centre is extremely important; number of infective episodes prior to BMT is inversely proportional to the chances of success. BMT in first three months of life where there was no or one episode of infection has an overall more than $90 \%$ chance of a cure. While each subsequent episode of severe infection reduces the success rate by $10 \%[28,29]$.

\section{CONCLUSION}

In conclusion, SCID is suspected in neonate where there is a history of an affected sibling or where there is a history of recurrent infections requiring hospitalization. Early diagnosis 
and timely referral to a specialist centre is lifesaving. BMT is curative when performed early in life. A focus on prevention of this disorder in the affected couple and identification of carriers of SCID is of utmost importance for prevention.

\section{CONFLICT OF INTEREST}

Declared none.

\section{ACKNOWLEDGEMENTS}

Declared none.

\section{REFERENCES}

[1] Al-Herz W, Bousfiha A, Casanova JL, et al. Primary immunodeficiency diseases: An update on the classification from the International Union of Immunological Societies Expert Committee for Primary Immunodeficiency. Front Immunol 2011; 2: 54 .

[2] Boyle JM, Buckley RH: Population prevalence of diagnosed primary immunodeficiency diseases in the United States. J Clin Immunol 2007; 27: 497-502.

DOI: $10.1007 / \mathrm{s} 10875-007-9103-1$

[3] Liang FC, Wei YC, Jiang TH, et al. Current classification and status of primary immunodeficiency diseases in Taiwan. Acta Paediatr Taiwan 2008; 49(1): 3-8.

[4] Baumgart KW, Britton WJ, Kemp A, French M, Roberton D. The spectrum of primary immunodeficiency disorders in Australia. J Allergy Clin Immunol 1997; 100: 415-23. DOI: 10.1016/S0091-6749(97)70257-4

[5] Rezaei N, Aghamohammadi A, Moin M, et al. Frequency and clinical manifestations of patients with primary immunodeficiency disorders in Iran: Update from the Iranian primary immunodeficiency registry. J Clin Immunol 2006; 26: 519-32. DOI: $10.1007 / \mathrm{s} 10875-006-9047-\mathrm{x}$

[6] Gathmann B, Grimbacher B, Beauté J, Dudoit Y, Mahlaoui N, Fischer A. ESID Registry Working Party. The European internet- based patient and research database for primary immunodeficiencies: Results 2006-2008. Clin Exp Immunol 2009; 157(1): 3-11. DOI: 10.1111/j.1365-2249.2009.03954.x

[7] National Institute of Population Studies (NIPS). Pakistan Demographic and Health Survey 2006-07. Islamabad: National Institute of Population Studies and Macro International Inc. 2008.

[8] Picard C, Al-Herz W, Bousfiha A, et al. Primary immunodeficiency diseases: An update on the classification from the international union of immunological societies expert committee for primary immunodeficiency 2015. J Clin Immunol 2015; 35: 696-726. DOI: 10.1007/s10875-015-0201-1

[9] Slatter MA, Gennery AR. Clinical immunology review series:
An approach to the patient with recurrent infections in childhood. Clin Exp Immunol 2008; 152: 389-96.

DOI: $10.1111 /$ j.1365-2249.2008.03641.x

[10] Subbarayan A, Colarusso G, Hughes SM, et al. Clinical features that identify children with primary immunodeficiency diseases. Pediatrics 2011; 127: 810-6.

DOI: $10.1542 /$ peds.2010-3680

[11] Modell V, Knaus M, Modell F, et al. Global overview of primary immunodeficiency: a report from Jeffrey Modell Centers worldwide focused on diagnosis, treatment, and discovery. Immunol Res 2014; 60(1): 132-44.

DOI: $10.1007 / \mathrm{s} 12026-014-8498-\mathrm{Z}$

[12] Alain F, Notarangelo LD, Neven B, Cavazzana M, Puck JM. Severe combined immunodeficiencies and related disorders. Nat Rev Dis Primers 2015; 1: Article number: 15061.

[13] Booth C, Hershfield M, Notarangelo L, et al. Management options for adenosine deaminase deficiency: proceedings of the EBMT satellite workshop (Hamburg, March 2006). Clin Immunol 2007; 123(2): 139-47. DOI: 10.1016/j.clim.2006.12.009

[14] Grunebaum E, Mazzolari E, Porta F, et al. Bone marrow transplantation for severe combined immune deficiency. JAMA 2006; 295(5): 508-18. DOI: 10.1001/jama.295.5.508

[15] Siala N, Azzabi O, Kebaier H, et al. Omenn syndrome: Two case reports. Acta Dermatovenerol Croat 2013; 21(4): 259-62.

[16] Abolhassani H, Sagvand BT. A review on guidelines for management and treatment of common variable immunodeficiency Expert Rev Clin Immunol 2013; 9(6): 561-75.

DOI: $10.1586 /$ eci.13.30

[17] Cunningham-Rundles C. How I treat common variable immune deficiency. Blood 2010; 116(1): 7-15.

DOI: $10.1182 /$ blood-2010-01-254417

[18] Davis G, Thrasher AJ. Update on hyper immunoglobulin M syndrome. Br J Haematol 2010; 149: 167-80. DOI: $10.1111 /$ j.1365-2141.2010.08077.x

[19] Gaspar HB, Qasim W, Davies EG, Rao K, Amrolia PJ, Veys P. How I treat severe combined immunodeficiency. Blood 2013; 122(23): 3749-58.

DOI: $10.1182 /$ blood-2013-02-380105

[20] Haddad E, Leroy S, Buckley RH. B-cell reconstitution for SCID: Should a conditioning regimen be used in SCID treatment? J Allergy Clin Immunol 2013; 131(4): 994-1000. DOI: 10.1016/j.jaci.2013.01.047

[21] Aiuti A, Roncarolo MG, Naldini L. Gene therapy for ADA-SCID, the first marketing approval of an ex vivo gene therapy in Europe: Paving the road for the next generation of advanced therapy medicinal products EMBO Mol Med 2017; 9(6): 737-40. DOI: $10.15252 / \mathrm{emmm} .201707573$ 
[22] Heuquet O. Hematopoietic stem and progenitor cell harvesting: Technical advances and clinical utility. J Blood Med 2015; 6: 55-67. DOI: 10.2147/JBM.S52783

[23] EBMT/ ESID guidelines for haematopoietic stem cell transplantation for PI. 2017; Available at: http://www.esid. org/bone-marrow-transplantation-updated-ebmtesid-guidelines-for-haematopoietic-stem-celltransplantation-for-pi-3500

[24] Fanos JH, Davis J, Puck JM. Sib understanding of genetics and attitudes toward carrier testing for X-linked severe combined immunodeficiency. Am J Med Genet 2001; 98: 46-56. DOI: 10.1002/1096-8628(20010101)98:1<46::AID-AJMG1008>3. $0 . \mathrm{CO} ; 2-\mathrm{K}$

[25] Saleem AF, Ali Khawaja RD, Shaikh AS, Ali SA, Mehdi Zaidi AK. Severe Combined immune deficiency syndrome. J Coll Physicians Surg Pak 2013; 23(8): 570-3.
[26] Javier FC III, Moore CM, Sorensen RU. Distribution of primary immunodeficiency diseases diagnosed in a pediatric tertiary hospital. Ann Allergy Asthma Immun 2000; 84: 25-30. DOI: 10.1016/S1081-1206(10)62736-6

[27] Gupta S, Madkaikar M, Singh S, Sehgal S. Primary immunodeficiency in India: A perspective. Ann N Y Acad Sci 2012; 1250: 73-9. DOI: 10.1111/j.1749-6632.2011.06353.x

[28] Wood P, Stanworth S, Burton J, et al. Recognition, clinical diagnosis and management of patients with primary antibody deficiencies: A systematic review. Clin Exp Immunol 2007; 149: 410-23. DOI: 10.1111/j.1365-2249.2007.03432.x

[29] Inamoto Y, Lee SJ. Late effects of blood and marrow transplantation. Haematologica 2017; 102: 614-25.

DOI: $10.3324 /$ haematol.2016.150250 